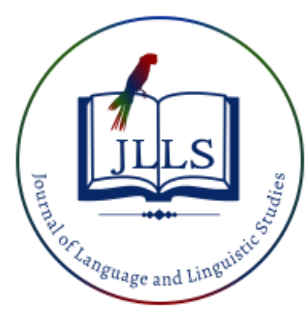

Available online at www.jlls.org

JOURNAL OF LANGUAGE

AND LINGUISTIC STUDIES

ISSN: 1305-578X

Journal of Language and Linguistic Studies, 17(4), 1907-1919; 2021

\title{
Polysemantic allusion in a polycultural dimension: Definition, structure and semantics (based on Pratchett's Discworld)
}

\author{
Nataliia Kravchenko a $^{\text {aD }}$, Oksana Chaika ${ }^{\text {b1 }}$ iD, Viktoriia Blidchenko-Naiko ${ }^{\text {(iD, }}$ \\ Tetiana Davydova ${ }^{\mathrm{d}}$ iD \\ a Kyiv National Linguistic University, Kyiv, Ukraine
${ }^{b}$ National University of Life and Environmental Sciences of Ukraine, Kyiv, Ukraine
${ }^{c}$ Bohomolets National Medical University, Kyiv, Ukraine \\ ${ }^{d}$ Sumy State Pedagogical University after A.S. Makarenko, Sumy, Ukraine
}

\section{APA Citation:}

Kravchenko, N., Chaika, O., Blidchenko-Naiko, V., \& Davydova, T. (2021). Polysemantic allusion: Definition, structure and semantics (based on Pratchett's Discworld). Journal of Language and Linguistic Studies, 17(4), 1907-1919. Doi: 10.52462/jlls.138

Submission Date:20/04/2021

Acceptance Date:28/07/2021

\begin{abstract}
The paper introduces the notion of polysemantic allusion in a polycultural dimension, explored in its semantic, structural and functional facets, based on intertextual contextual interpretative, structural, taxonomic, archetypal analyses added by some inferential pragmatics tools. Polysemantic allusion (PA) is defined as an intertextuality device, which combines two and more facultatively decoded meanings due to their association with more than one precedent source situations, texts or phenomena. The markers of PA include the modified and altered precedential names, designating the literary text or extra-textual sphere of denotation, symbolic or archetypal references of precedential situation or text; a science-associated terms or their structural part, which must satisfy the ambiguity and optional decoding of the precedential sources triggered by the PA. The markers of polysemantic allusion may be one, two- and multicomponent with each structural part capable of creating additional allusive connotations in its unfolding in further context. PA involves several levels of semantic interpretation, which correlate with various precedent texts and differ in degrees of implicitness of the allusive meanings, interpreted with an attraction of the optimally relevant context, implicating, strengthening, confirming or contradicting the hypothetic allusive assumptions. Semantic components of PA may encompass hypertextual references providing coherent relations between Pratchett's novels, and architextual meanings associated with parodying various genres.
\end{abstract}

Keywords: polysemantic allusion; allusive markers; polycultural dimension; degrees of implicitness; allusion structure; contextual effects

\section{Introduction}

Pratchett's texts are remarkable for their comprehensive intertextuality, which turns them into a multi-layered semiotic unity, where the content level is parameterized by deeper semantic scopes. Such an "encodedness" is primarily determined by the parody nature of all Pratchett's novels. There,

\footnotetext{
1 Corresponding author.

E-mail address: oxana.chaika@yahoo.es
} 
the author parodies "from the inside" the fantasy genre itself, human society, especially the realities and values of Western civilization, as well as the world literary classics, modern cinematography, music, science, art, even himself, or rather, his own style, plots, and characters of his Discworld novels. Trusting, stupid, sometimes criminal, but, as a rule, essentially innocent and naive inhabitants of the Discworld are inhabitants of our own world, viewed from the postmodern parody perspective: "humans need fantasy to be human. to be the place where the falling angel meets the rising ape" (Hogfather, p. 422).

In addition to parodic-based intertextuality in a polycultural scope, numerous allusive implicatures are very largely due to the author's identity, an essential component of which is the writer's comprehensive erudition. Both the factors determine the widespread use of allusions in Pratchett's novels, especially in their indirect manifestations, which are the main means of semantic parametrization in the Discworld series of novels.

Of greatest interest, in this regard, are indirect implicit allusions, which, in contrast to direct allusions and reminiscences, may trigger different inferences and interpretations, hinting simultaneously at several precedent texts and situations. That considered such a polysemantic allusion (PA) remains unexplored in linguistic studies, thus, the paper aims at specifying this polycultural phenomenon in terms of its structural properties, semantics, types and associated precedent sources. Polyculturality of polysemantic allusion (in Pratchett's Discworld, in particular) envelopes in the intercultural engagements within the global geographical area. It expressively underlines the relevant symbolic and archetypal similarities between any groups of a poly-lingual community, where selfidentifying boundaries are distinct, however, become blurred for easy and smooth cognitive absorption by different peoples.

Since Pratchett's novels fit, first, into the framework of the postmodern paradigm, the paper employs a broad, primarily postmodernist approach to understanding the text as a "culture" and a culture as a text. In other words, Pratchett's texts are part of various semiospheres in the semiotic universe of culture and civilization - not only the semiosphere of literary texts and fantasy texts, in particular, but also the semiotic space of cinema, science, mythology, art, etc. Hence, they are seen in their largely vast expression of polyculturalism as a global phenomenon in cinematography, world drama, and world literature and so on.

The interpretation of polysemantic allusions in Pratchett's texts is based primarily on universal knowledge, which constitutes a component of world literature, culture and civilization and is targeted at representatives of different national, linguistic, and cultural communities. Pratchett himself calls such knowledge "white" ("white knowledge") based on universal cultural signs in the entire polycultural dimension. However, this white knowledge is not always a well-known proto-text, which can be easily recognized by readers due to their collective background knowledge. Some of the prototexts may be little known, and/or known to a very narrow circle of specialists, or the proto-texts may be "packed together" like a nesting doll: the interpretation of one of the allusive proto-texts "opens" other lesser- known semantic levels that is characteristic of polysemantic allusion, in particular.

\subsection{Literature review}

In its theoretical premises, the research is based on those intertextuality studies within linguistic and interdisciplinary framework that focus on the concept of intertextuality, its taxonomy, as well as the level of investigation of intertextuality in Pratchett's texts.

The study of intertextuality is an inherent part of scientific research within the postmodernist paradigm, and, especially in the environment of semioticians poststructuralists. J. Derrida, who emphasized the openness of the text to infinity, introduces the principle of "decentralization" of the 
text structure with infinite references in connection with one text to another, and to all texts in general. The boundless associativity intertextuality of the text, formed from the anonymous, elusive and at the same time already read quotations "without quotation marks", is highlighted by R. R. Barthes in his famous work From the work to the text (1977, p. 155-164). Next, J. Genette (1997), influenced by R. Barthes's ideas, introduces a five component classification of intertextual connections, which is relevant for the linguistic research today.

In his famous work Palimpsests: literature in the second degree, J. Genett identifies the five types of transtextual connections:

1) Intertextuality as a connection of two or more texts, the presence of one text in another (explicit citation, implicit plagiarism and allusions),

2) Paratext as a connection of the text with its title, preface, afterword, notes, epigraph, illustrations, etc.,

3) Metatextuality as a commentary on the previous text,

4) Hypertextuality as ridiculing or parodying of one text by another,

5) Architecturality as a genre connection of texts of one type / class (poem with poem, prose with prose, etc.) (Genette, 1997, pp. 1-7).

Here it is important to note that Pratchett's hypertextuality (the third type of Barthes' transtextuality) is not always reduced to parody. It is akin to the modern post-postmodern concept of hypertext as a kind of multidimensional space of semantic possibilities, which can be reached through a jump, a hyperlink that in our case is an allusion. The entire Discworld is a single semiotic space connected by internal intertextual connections or, using Barthes' words, such a text is permeated with a network of countless intertwining internal passages, and one can enter it through many entrances (i.e. allusions to other texts of the cycle, providing its internal semantic coherence and, at the same time, opening up the possibilities of additional semantic increment - the authors of this article) (Barthes, 1975, p. 14).

Considering the object and purpose of this research, it also matters to demarcate the terms of 'proper' and 'facultative' intertextuality (Majkiewicz, 2008, p. 20; Nycz, 2005, p. 85-86). The latter implies the possibility of irregular pattern in decoding intertextuality, which is characteristic of polysemantic allusion that is under analysis in this article. It is equally important to distinguish between explicit (quote and reference) and implicit (plagiarism and allusion) intertextual relations (Pieguet Gro, 2002), as well as the relationship of derivation (op. cit), including the below:

(a) Transformation in the form of parody (a plot is changed while the style is preserved) and burlesque travesty (the work is transformed into a low style while preserving its plot),

(b) Stylization (the original text is not subject to distortion, only its style is imitated).

Given the parody feature of Pratchett's intertextuality, it is also worth mentioning the concept of parody Y. Tynjanov, which is consonant with the above classification of derivation types by N. PiegeGro. Particularly, the scientist distinguishes between two types of intertextual relations - stylization and parody. While the stylization presupposes a similarity to previous texts, the parody implies the texts collision, which results in deep semantic shifts that generate a mechanism of meaning making, identical to interpretation of intertextual meanings (Tynjanov, 1977, p. 201).

As a summary of the above classifications from the perspective of this study, it can be noted that the implicit polysemantic allusion, which is under consideration in this paper, is the space of intersection, figuratively speaking, of all these taxonomic sets. It combines the characteristics of intertextual, hypertextual, and architextual device; it is implicit, indirect, optional, and parodic. 
However, it is precisely the coverage of the characteristics of various taxonomies in one phenomenon that determines the scientific novelty and relevance of the research. In addition, the polysemantic property of allusion, which, in fact, determines the various levels of its implicitness, the facultativeness of interpretation and multifunctionality as a means of simultaneously intertextuality, hypertextuality, and architextuality, has yet to be studied either within a linguistic or interdisciplinary framework.

Similarly, polysemantic allusion has not been the focus of the intertextuality research in Pratchett's texts yet. Such mainly consider the form and function of intertextuality in the witch-sequence of Terry Pratchett's Discworld novels (Andersen, 2006), interaction of Discworld with Shakespeare's texts (Miller, 2011), a parody aspect of intertextuality (Butler, 1996), its connection with the problem of translating Pratchett's texts (Rzyman, 2017).

\subsection{Research questions}

The articles aims to introduce and define the notion of polysemantic allusion by scrutinizing its semantic, structural and functional parameters. The purpose involves solving several interrelated tasks, including: (a) identification of the markers of PA and their structural properties; (b) revealing the levels of semantic interpretation, triggered by PA, in their correlation with precedent texts and phenomena; (c) specification of implicitness degrees of the allusive meanings, marked by PA; (d) clarification of PA associated with hypertextual and architextual references.

\section{Method}

\subsection{Texts}

The data under analysis consist of text fragments collected from T. Pratchett's novels The Colour of Magic, Hogfather, Wyrd Sisters, Mort, Eric, Equal Rites from his famous cycle Discworld. The selection of material has been based on the markers of intertextuality, evoking a precedent situation as a certain cognitive invariant, associated with a set of differential denotative features and connotations. Such markers may involve key words or concepts designated literally, metaphorically, symbolically, representing paradigmatic synonyms, hyponyms or hyperonyms, or reduced variants of precedent words:

(a) Any nomination referring to recognizable socio-cultural phenomenon,

(b) A term or its structural-semantic component referring to a scientific theory,

(c) Symbolic or metaphoric designations of precedential situation or text,

(d) Precedential name or its denotative substitute referring to a certain literary text or extra-textual situation.

Considering the object and purpose of our research, focused on polysemantic allusion, the main criteria for the selection of material is the obligatory ambiguity of the identified allusive meaning, i.e. its association with more than one precedent situation, text, phenomenon, etc. For example, an utterance

(1) "Let him but get to Chimera" (The Colour of Magic, p. 43)

contains the allusion to mythological precedential character "Chimera", a phenomenon that is part of the "universal" cognitive space and, accordingly, is easily recognized by any reader, regardless of their lingual and cultural context. That means that at first glance this allusion may hardly fall within the scope of our research, since it is explicit. At the same time, the precedential name "Chimera" presupposes here double meaning and / or ambiguous interpretation as it triggers at least two allusive 
meanings referred to a monster from the Greek mythology and to Cimmeria, Conan the Barbarian's mythical homeland. The latter meaning is additionally foregrounded by spatial deictic marker get to.

\subsection{Instruments}

The article is based on integrative qualitative analysis that integrates the below enlisted:

(a) The proper intertextual analysis (Allen, 2011; Orr, 2003; Plett, 1991), applied to reveal source texts and precedential situations and phenomena, triggered by implicit allusive markers, added by elements of hypertextual analysis to specify the cohesive function of allusion in semiotic-semantic space of Pratchett's cycle of novels, as well as by architectural analysis in identifying allusions parodying various genres,

(b) Contextual interpretative analyses, which aim at identifying the meanings encoded by allusions considering particular contextual environments (Kravchenko et al, 2021, 2021a; Kravchenko et al, 2020, 2020a),

(c) Elements of structural and taxonomic analysis, used to propose structure based taxonomy of implicit allusion,

(d) Elements of archetypal analysis (Kravchenko, Snitsar, 2019), in order to encode the archetypal motifs, symbols, plots underpinning the polysemantic mythological allusions,

(e) Elements of analysis based on inferential pragmatics tools, using the concept of optimal relevance and contextual effects (Sperber \& Wilson, 2001) of strengthening, confirming, implication, and contradicting the assumptions triggered by PA. That considered the ostensive-inferential model suits any kinds of communications, including the literary discourse as a kind of communicative activity, guided by pragmatic universal conventions (Kravchenko, Yudenko, 2019).

\subsection{Data collection procedures and analysis}

The paper introduces the concept of polysemantic allusion in its structural, semantic, and taxonomic facets. The collected data are analyzed on the four consecutive stages of analysis:

1. The fantasy texts were processed via continuous sampling method, aimed at identification the implicit allusions markers.

2. Identified allusions were distributed respective of their markers and spheres of allusive reference.

3. Polysemantic allusions were interpreted upon their structure with its explication in structural formulas.

4. The identified structural types were specified in relation to their multicomponent semantics and its associated meanings of the first, second, third, etc. orders.

\section{Results and Discussion}

\subsection{Polysemantic allusion markers: structure and functions}

The identified markers of polysemantic allusions differ in their structure, source texts or situations, and degree of implicitness. One-component marker is represented either by a precedential name (Chimera in (1), Gingo below in (5) referring to socio-cultural phenomenon, mythological character, etc.), or by part of a term referring to a scientific theory. The latter links to the interpretation of allusive meaning, which is associated with the contextual effects of strengthening or confirmation of the interpretative hypothesis, triggered by a fragment of term as an ostensive stimulus. 
For example, the adjective steady in an utterance

(2) "the theory that A'Tuin had come from nowhere and would continue at a uniform crawl, or steady gait" (The Colour of Magic, p. 8)

serves as a marker of a precedent situation related to the cosmological "steady-state" theory - one of the scientific theories substantiating the theory of the origin of the Universe. However, this contextual implication is actualized when correlating with the previous context, i.e. it is the result of contextual dependent strengthening:

(3) The early astrozoologists, hauled back from their long dangle by enormous teams of slaves, were able to bring back much information about the shape and nature of A'Tuin and the elephants but this did not resolve fundamental questions about the nature and purpose of the universe (The Colour of Magic, p. 8).

The most frequent are the two-component allusive markers, referring to literary texts, mythological texts or precedential situations. For example, in (4) the implicit allusion is marked by denotative substitute of precedential name referring to a source literary text:

(4) an alumnus of Unseen University (The Colour of Magic, p. 20)

Due to the synonymic semantic relations of the words "Unseen" and "Invisible" in combination with the nouns relating to the same hyperonim "educational institution", "Unseen University" involves the associations with "Invisible College" from Neil Gaiman's Sandman comic Brief Lives. However, the name of the Unseen University, allusively recurrent in various novels of Discworld, can also be interpreted as an allusion to various secret esoteric societies popular in the 20th century, which also tend to be invisible to society.

In (5) implicit allusion is built on the association in the same context of the two denotata: the cat and its smile, which refers to the Cheshire cat in the source text - Lewis Carroll's Alice's Adventures in Wonderland the closest prototype.

(5) "Greebo's grin gradually faded, until there was nothing left but the cat. This was nearly as spooky as the other way round." (Wyrd Sisters, p. 142).

At the same time, in his globally parodic style, Pratchett paradoxically transforms a well-known quotation, bringing it to almost an absurdity and alogism, contrary to common sense (since in fact, ordinary cats, with the exception of the Cheshire one, do not smile). In the transformed version, as can be seen from the example, it is not the cat that completely disappears, but the smile itself, which provides the effect of the defeated expectancy due to the mismatch of the inference with the background knowledge of the reader.

Thus, in this case Pratchett parodies ex adverso the very style of postmodernism (an adherent of which he, by the way, is). In any case, his all-encompassing parodic manner fits well into the postmodern artistic and aesthetic paradigm with its inherent simulacra, originality and semantic deconstruction. A smiling cat is too simple for the postmodernism world perception, a smile without a cat is a frequent reminiscence and, therefore, also quite trivial, but a cat without a smile is so unoriginal that it just frightening or spooky. There is a kind of destruction of the internal form of the image of the "smile of the Cheshire cat" with the reversion of the connotations on the rating scale "fine-awful". A Cheshire cat with a smile is a symbol of charm and friendliness while a cat without a smile is terrible.

As in the examples analyzed above, each of the structural components of the allusion is capable of creating additional semantic parameterization. 
In particular, the possible facet of intertextual meanings is actualized by key allusive component "cat", found in its full precedential version of a Cheshire cat. It is famous for slowly vanishing until only its grin remains, in a novel Mort (1987), published one year before Wyrd Sisters (1988).

(6) "just like a Cheshire cat only much more erotic." (Mort, p. 69).

Correspondingly, the "nothing left but the cat" in (5) is additionally based on hypertextual cohesive associations with other texts of the Discworld, ensuring its integrity as a single semiotic space.

It is important to note that the images of the "Cheshire cat" and "the smile of the Cheshire cat" have become one of the cultural archetypes. They are disseminated in Disney cartoons, computer games, in the Chronicles of Amber fantasy series by Roger Zelazny, in the fantasy novel Automated Alice by Jeff Noon, in Andrzej Sapkowski's The Golden Afternoon, a postmodern retelling of Alice's Adventures in Wonderland, where the story is narrated on behalf of the Cheshire cat. This means, on the one hand, the possible architectural implication of the Pratchett's allusion, which is aimed at parodying the disseminated archetypal characters and plots. On the other hand, the allusion to the smile of the Cheshire cat can acquire additional semantic connotations not even intended by the author - as they purely depend on the cognitive base of the reader and the contexts that formed it. For example, PA can evoke negative connotations associated with the image of a cat in Through the Looking Glass by Frank Beddor or trigger the "appearance" associations with the tattooed, skinny Cheshire Cat from the video games American McGee's Alice and Alice: Madness Returns.

In the latter case, the associative meaning becomes the contextual effect of strengthening another structural component of the Pratchett's allusion, marked by a name Greebo in Greebo's grin, that designates the sort of man who would like to join a biker movement Hell's Angel in the seventies but does not have enough style for it. Indeed, a cat that does not smile lacks even the charm of a Cheshire cat and is distinguished by a complete lack of style at all, clear lack of style. On the other hand, this structural component of the allusion fulfills a text-forming function in the further text of the novel, since later the Nanny really turns her cat into a man so that he can help her in a certain situation. Moreover, the external description of the reincarnated Griebo coincides with the image of the American representatives of Greebo - long haired, with a sloppy look and leather clad.

\subsection{Polysemantic allusion semantic ambiguity: levels of interpretation}

The highest degree of implicitness is characteristic of Pratchett's allusions to ancient mythology, marked by symbolic or metaphoric designations of a precedential source situation or text, which decoding is facultative, requiring a considerable amount of erudition. However, even the recognition of the proto-text, to which one or another allusion refers, does not mean the inference all the semantic facets, triggered by allusion as is exemplified below by an implicit allusion to ancient Greek mythology from Pratchett's novel Eric:

(7) A few bees buzzed around him. Like all beekeepers, Death wore a veil

Now Death was inspecting his bees, gently lifting the combs in his skeletal fingers (Eric, p.1).

Description of the beekeeper-Death, is, in our opinion, an allusion to the archetypal plot related to ancient Greek myth of Persephone and her bee priestesses. Bees (Melissa) in ancient times were called priestesses of Demeter and Persephone, who participated in the Eleusinian mysteries. Further, Persephone herself, the goddess of fertility and the kingdom of the dead, was called Melitodes, i.e. "honey".

PA, associated with the mythological proto-text, forms only one of the possible semantic layers of the text fragment. The multifaceted meaning of the allusion is determined by its correlation with a set 
of other precedent texts - enclosed in the semiosphere of literary texts of various genres, eras and literary-aesthetic paradigms (that also confirm the plot archetypal nature).

In particular, to create the image of the death beekeeper Pratchett may have also used the famous text of Osip Maldenstam, for which, in turn, the ancient Greek myth served as a source text for the borrowed allusion.

For your delight, take from my palms

A little sun, a little honey, As Persephone's bees have ordered us

(O. Mandelstam)

The implicit allusion is two-component, formed by associating the symbolically based connotations, triggered by the words "bees" and "death", which, however, are activated only in their syntagmatic proximity in the local textual context. The associated key components are capable of evoking additional allusive associations either together or separately.

In particular, the structural imagery expansion of the component "bees" results in even more optional associative subtextual meanings, which interpretation completely depends on the erudition of the reader. In this vein, the subsequent imagery describing the bees of Death may be associated, in addition, with flies from the play Flies by J. P. Sartre, which, in turn, is based on the plot and semantic basis of the ancient Greek myth about Orestes:

(8) The bees of Death are big and black, they buzz low and somber, they keep their honey in combs of wax as white as altar candles (Eric, p.1).

Thus, an indirect polysemantic allusion presupposes several levels of semantic interpretation, correlating with various precedent texts. Each subsequent level is characterized by an increase in the degree of implicitness of the allusive meaning and corresponding semantic parameterization of the Pratchett's texts.

Typical structures of indirect polysemantic allusion in novels under consideration rely on the formula as provided in Table 1:

Table 1. Typical structures of indirect polysemantic allusion (PA) in novels

\begin{tabular}{lc}
\hline PA & Meaning level \\
\hline IndirectA1 & $1^{\text {st }}$ \\
implA1 (1) & $2^{\text {nd }}$ \\
implA1 (2) & $3^{\text {rd }}$ \\
\hline
\end{tabular}

The formula can be modified with the reduction or, vice versa, additional semantic parameterization of one or more structural components, or a lateral branching of the scheme with the addition of other allusions, as shown by the analysis of the allusion in (9).

(9) "through the fathomless deeps of space swims the star turtle Great A'Tuin, bearing on its back the four giant elephants who carry on their shoulders the mass of the Discworld" (Wyrd Sisters, p. 4)

The given example presents a three-component allusion, which includes three obligatory structural components: giant turtle, elephants, land (or another world) on elephants, which associative links refer to a mythologically based source proto-text.

The above allusion performs a special meaningful function in Prattchet's cycle as it opens all of its novels. Despite the variety of their content and plot, all the texts begin with the same description of the structure of the universe, enclosing the Discworld and presenting a huge disk, resting on the backs of 
four elephants, standing on the back of a gigantic turtle named A'Tuin. In this case, an allusion to Hindu cosmology, according to which the world is based on a turtle, an elephant or a snake, serves not only as a means of intertextuality, but also as a hypertextual device, which provides the semantic coherence of all the texts of the novels, by placing their semiotic spaces within a single chronotope of the ancient Discworld.

At the same time, one of the semantic aspects of the allusion - i.e. the emphasis on the two dimensional nature of Pratchett's world, associates it with a fantasy genre cosmogony, which often presupposes a flat world (cf. Tolkien's legendarium or The Voyage of the Dawn Treader from The Chronicles of Narnia). In this case, the intertextual aspect, triggered by allusion, is added not only by the hypertextual facet (ensuring the structural and semantic coherence of the cycle texts), but also the arch-textual references (in G. Janette's terms).

Interaction of the various facets of the implicit polysemantic allusion is shown by an allusive formula 2:

Table 2. Allusive formula 2

\begin{tabular}{lcc}
\hline PA & Meaning level & Type \\
\hline IndirectA1 & $1^{\text {st }}$ & $\begin{array}{c}\text { Hindu mythology- } \\
\text { based }\end{array}$ \\
ImplA1 (1) & $2^{\text {nd }}$ & hypertextual \\
& structural semantic \\
& coherence of texts \\
& of the same \\
& allusion-based \\
& chronotope \\
& & arch-textual \\
& & parodying of \\
& & scientific genres \\
& & \\
& & \\
\end{tabular}

The structural-semantic "unfolding" of the particular structural component of allusion, related to giant turtle, in specific contexts results in additional allusive connotations associated with the nonliterary semiospheres of science, feature films, etc.

(10) This theory was popular among academics. An alternative, favoured by those of a religious persuasion, was that A'Tuin was crawling from the Birthplace to the Time of Mating, as were all the stars in the sky which were, obviously, also carried by giant turtles. When they arrived they would briefly and passionately mate, for the first and only time, and from that fiery union new turtles would be born to carry a new pattern of worlds. This was known as the Big Bang hypothesis (The Colour of Magic, p.1).

The above fragment represents an expanded polysemantic allusion, which semantic components paradoxically combine a reference to Hindu cosmogony myths and to the modern generally accepted cosmological model describing the early development of the universe (this was known as the Big Bang hypothesis). In addition, allusion triggers ironic connotations parodying the ideology of scientism that has developed in modern industrial societies and strives to extend "science-bound" approach to all types of human development of the world. Thus, with the help of expansionmodifications of the mythology-based allusion, Pratchett achieves a humorous effect, building a parallel parody texts aimed at ridiculing modern society, which has formed a kind of cult of science. In 
the latter case, the arch-textual ones, associated with the parody of scientific genres, add the intertextual connections.

It is as shown by an allusive formula below:

Table 3. Allusive formula 3

\begin{tabular}{lcc}
\hline PA & Meaning level & Type \\
\hline IndirectA1 & $1^{\text {st }}$ & $\begin{array}{c}\text { Hindu mythology- } \\
\text { based }\end{array}$ \\
ImplA1 (1) & $2^{\text {nd }}$ & $\begin{array}{c}\text { conditional proto- } \\
\text { text source of } \\
\text { scientific theories } \\
\text { of the "Big Bang" }\end{array}$ \\
& $3^{\text {rd }}$ & $\begin{array}{c}\text { architextual } \\
\text { parodying of } \\
\text { ImplA1 (2) }\end{array}$ \\
& & scientific genres \\
\end{tabular}

In addition, the hyper-archi-intertextual allusion to the Indian mythology becomes a special allegorical framework to involve another intermedial simile-based allusion, relating in particular to films and TV series, which may be explicated by the following formula:

Table 4. Allusive formula 4

\begin{tabular}{lcc}
\hline PA & Meaning level & Type \\
\hline IndirectA1 & $1^{\text {st }}$ & $\begin{array}{c}\text { Hindu mythology- } \\
\text { based }\end{array}$ \\
ImplA1 (1) & $2^{\text {nd }}$ & hypertextual \\
& structural semantic \\
& coherence of texts \\
& of the same \\
& allusion-based \\
& chronotope \\
& & arch-textual \\
& & parodying of \\
& $3^{\text {rd }}$ & genres of epic \\
& space opera \\
& & \\
& &
\end{tabular}

(11) Then it comes into view overhead, bigger than the most unpleasantly-armed starcruiser in the imagination of a three-ring-filmmaker: a turtle, ten thousand miles 15 long (Equal Rites, p.1) - a polysemantic allusion referring to the cosmology of the Hindu myth, to the cosmology of hypertext of the entire cycle of Pratchett's novels and to George Lucas' Star Wars movie.

In the latest example, the allusion is marked with a multicomponent marker-comparison with five associated components, which in their combination trigger the allusive inference: armed starcruiser, filmmaker, a turtle ten thousand miles 15 long. 


\section{Conclusions}

Based on the accepted approaches to the concept of intertextuality, its forms and taxonomies, the paper introduces the notion of polysemantic allusion in a polycultural dimension, specified in its semantic, structural and functional facets. For that purpose, an integrative method that involve intertextual analysis, added by elements of contextual interpretative, structural, taxonomic, archetypal analyses together with certain inferential pragmatics tools, has been applied in four consecutive stages of analysis - with the achievement of the following corresponding results.

Polysemantic allusion is an intertextuality device, which combines two and more facultatively decoded meanings due to their association with more than one precedent source situation, text, phenomenon, etc.

The markers of PA include precedential name, often in its modified and altered version, to designate the literary text or extra-textual sphere of denotation, symbolic or metaphoric designations of precedential situation or text; a science-associated term or its structural part- provided that the triggered precedential sources and their associated meanings are ambiguous and optional for decoding.

The markers of polysemantic allusion may have one-component, two-component and multicomponent structure - each structural component being capable of creating additional allusive connotations in its "unfolding" in further context.

Polysemantic allusion presupposes several levels of semantic interpretation, correlating with various precedent texts. Each subsequent level is characterized by an increase in the degree of implicitness of the allusive meanings, which are inferred, interpreted and reinterpreted with an attraction of the optimally relevant context, integrating the textual and cognitive-presuppositional base, - with implication, strengthening, confirmation or contradiction of the hypothetic allusive assumptions.

Semantic components of PA may involve hypertextual references as a means of ensuring semantic coherence between different novels by Pratchett, and architextual meanings associated with parodying various genres.

\section{References}

Allen, G. (2011). Intertextuality. New Critical Idiom. 2nd edition. London, New York: Routledge.

Andersen, D. (2006). Bewitching Writing. An Analysis of Intertextual Resonance in the Witch sequence of Terry Pratchett's Discworld. Aalborg University. Fl346rdigtspeciale.doc

Barthes, R. From Work to Text. (1977). Image-Music-Text (155-164). London: Fontana Press. Barthes-image_music_text.pdf (grrrr.org)

Barthes, R. (1975). S/Z.: An Assay. Hill and Wang.

Butler, A. M. (1996). "Terry Pratchett and the Comedic Bildungsroman". The Review of Science Fiction, Issue 67, $56-62$.

Genette, G. (1997). Palimpsests: literature in the second degree. (Ch. Newman \& C. Doubinsky, Trans.). L; Lincoln, NE: University of Nebraska Press.

Derrida, J. (1997). Of Grammatology. Baltimore \& London: Johns Hopkins University Press, corrected edition, trans. Gayatri Chakravorty Spivak. 
Kravchenko, N., Zhykharieva, O., Kononets, Y. (2021). Rap artists' identity in archetypal roles of Hero and Seeker: A linguistic perspective. Journal of Language and Linguistic Studies, 17(1), 646- 661. Doi: 10.52462/jlls.44

Kravchenko, N., Prokopchuk, M., Yudenko, O. (2021a). Afro-American rap lyrics vs fairy tales: possible worlds and their mediators. Cogito. Multidisciplinary research journal, XIII (1 / March), 146-168. https://cogito.ucdc.ro/cogito_nr_1_2021.pdf

Kravchenko, N., Snitsar, V., Blidchenko-Naiko, V. (2020). Paradoxes of rap artists' role identity: Sage, Magician or Trickster? Cogito. Multidisciplinary research journal, XII (1/March), 179-195. https://cogito.ucdc.ro/COGITO\%2027\%20martie\%202020.pdf

Kravchenko, N., Davydova, T., Goltsova, M. (2020a). Comparative Study of Fairy Tale and Rap Narratives: Spaces Specificity. Journal of History, Culture and Art Research, 9(3), 155-167. doi: http://dx.doi.org/10.7596/taksad.v9i3.2747

Kravchenko, N., Snitsar, V., (2019). Cultural archetypes in the construction of "possible worlds" of modern African-American rap (based on Kendrick Lamar's texts). Euromentor Journal, X(4), 8092. Euromentor Journal december 2019.doc (ucdc.ro)

Kravchenko. N., Yudenko, A. (2019). Communicative conventions and literary text: specifics of interplay. Science and Education. A New Dimension. Philology, VII(62), Issue 211, 26-28. DOI:10.31174/SEND-Ph2019-211VII62-06

Majkiewicz, A. (2008). Intertekstualnosc - implikacje dla teorii przekladu. PWN, Warszawa.

Mandelstam, O. Just for joy, take from my palms (1973) The Complete Poetry of Osip Emilevich Mandelstam, translated by Burton Raffel and Alla Burago. State University of New York Press (USA).

Miller, Jenna (2011). "Terry Pratchett's Literary Tryst with Shakespeare's Macbeth: A Postmodernist Reading with a Humanist Guide". University of South Florida, Outstanding Honors Theses. Paper 19. http://scholarcommons.usf.edu/honors_et/19

Nycz, R. (2000). Tekstowy świat. Poststrukturalizm a wiedza o literaturze. Warszawa, Kraków.

Orr M. (2003). Intertextuality: Debates and Contexts. Cambridge: Polity Press. 256 p.

Piégay-Gros, N. (2002). Introduction à l'intertextualité. Nathan Université.

Plett, H. (1991). Intertextuality. Research in Text Theory (ed. by H. Plett). New York: Walter de Gruyter. P. 3-29.

Pratchett, T. (1985). The Colour of Magic. London: Corgi.

Pratchett, T. (1997). Hogfather. London: Corgi.

Pratchett, T. (1989). Wyrd Sisters. London: Corgi.

Pratchett, T. (1988). Mort. London: Corgi.

Pratchett, T. (1990). Eric. London: Gollancz.

Pratchett, T. (1987). Equal Rites. London: Corgi.

Rzyman, A. (2017). The Intertextuality of Terry Pratchett's Discworld as a Major Challenge for the Translator. Cambridge Scholars Publishing.

Sperber, D., \& Wilson, D. (2001). Relevance: Communication and cognition (2nd ed.). Beijing: Foreign Language Teaching and Research Press. 
Tynjanov, Y. (1977). Poetyka. Istorija literatury. Kino [Poetics. History of literature. Cinema]. Moskva: Nauka. P. 284-309. [in Russian].

\section{AUTHOR BIODATA}

Nataliia Kravchenko, Doctor of Philology, Professor at I.V. Korunets Department of English and German Philology and Translation, Kyiv National Linguistic University, Ukraine. The research interests are course analysis, theoretical pragmatics, identity and role analysis, intercultural communication, cognitive and conceptual analysis.

Oksana Chaika, $\mathrm{PhD}$ (linguistics) supervises scholar researches, gives lectures and tutorials as Professor (Associate) at the National University of Life and Environmental Sciences of Ukraine. She is also Chief International Relations and Liaison Partner at Crowe Global, an international accountancy and consultancy network ranked eighth in the world. Combining theory and practice, her principal scholar interests connect to a wide variety of areas: from syntax and semantics, to terminology studies, languages for specific purposes, compatibility of linguistics findings and digital innovations, to education, language and communication, language acquisition, and discourse.

Viktoriia Blidchenko-Naiko, PhD (linguistics) works as Associate Professor at Department of Ukrainian Studies, Bohomolets National Medical University, Ukraine. Her research interests are cognitive linguistics, archetypal symbolism, conceptual metaphor.

Tetiana Davydova, PhD (linguistics), senior Lecturer at the Department of English Practice at the Sumy State Pedagogical University named after A.S. Makarenko. She engages into researches on cognitive linguistics, and discourse analysis. 